\title{
Structured and Systematic Team and Procedure Training in Severe Trauma: Going from 'Zero to Hero' for a Time-Critical, Low-Volume Emergency Procedure Over Three Time Periods
}

\author{
Maryam Meshkinfamfard $^{1} \cdot$ Jon Kristian Narvestad ${ }^{1,2} \cdot$ Johannes Wiik Larsen $^{1} \cdot$ Arezo Kanani $^{1} \cdot$ \\ Jørgen Vennesland $^{3} \cdot$ Andreas Reite $^{2,3} \cdot$ Morten Vetrhus $^{3,4} \cdot$ Kenneth Thorsen $^{1,2,5} \cdot$ Kjetil Søreide $^{1,5}$ (1)
}

Accepted: 16 January 2021 / Published online: 10 February 2021

(C) The Author(s) 2021

\begin{abstract}
Background Resuscitative emergency thoracotomy is a potential life-saving procedure but is rarely performed outside of busy trauma centers. Yet the intervention cannot be deferred nor centralized for critically injured patients presenting in extremis. Low-volume experience may be mitigated by structured training. The aim of this study was to describe concurrent development of training and simulation in a trauma system and associated effect on one timecritical emergency procedure on patient outcome.

Methods An observational cohort study split into 3 arbitrary time-phases of trauma system development referred to as 'early', 'developing' and 'mature' time-periods. Core characteristics of the system is described for each phase and concurrent outcomes for all consecutive emergency thoracotomies described with focus on patient characteristics and outcome analyzed for trends in time.

Results Over the study period, a total of 36 emergency thoracotomies were performed, of which 5 survived (13.9\%). The "early" phase had no survivors (0/10), with 2 of $13(15 \%)$ and 3 of $13(23 \%)$ surviving in the development and mature phase, respectively. A decline in 'elderly' ( $>55$ years) patients who had emergency thoracotomy occurred with each time period (from $50 \%, 31 \%$ to $7.7 \%$, respectively). The gender distribution and the injury severity scores on admission remained unchanged, while the rate of patients with signs on life (SOL) increased over time.

Conclusion The improvement over time in survival for one time-critical emergency procedure may be attributed to structured implementation of team and procedure training. The findings may be transferred to other low-volume regions for improved trauma care.
\end{abstract}

Supplementary Information The online version contains supplementary material available at (doi:https://doi.org/10.1007/ s00268-021-05980-1).

Kjetil Søreide

ksoreide@mac.com

1 Department of Gastrointestinal Surgery, Stavanger University Hospital, P.O. Box 8100, 4068 Stavanger, Norway

2 Section for Traumatology, Surgical Clinic, Stavanger University Hospital, Stavanger, Norway
3 Department of Surgery, Vascular \& Thoracic Surgery Unit, Stavanger University Hospital, Stavanger, Norway

4 Department of Clinical Science, University of Bergen, Bergen, Norway

5 Department of Clinical Medicine, University of Bergen, Bergen, Norway 


\section{Introduction}

Trauma is a major health burden worldwide [1]. Severe injuries may cause sudden change to vital functions with risk of imminent death if no intervention or appropriate resuscitation takes place [2]. Certain emergency procedures are considered lifesaving if and when performed for the right indications and with appropriate training [3]. Resuscitative emergency thoracotomy is one such procedure indicated for severely injured patients in extremis, but with variation in reported outcomes and its use still being debated [4-6]. Notably, outcomes are demonstrated to be better in large, urban, busy trauma centers, often with a high rate of penetrating injuries [6].

Historically, survival after resuscitative thoracotomy for blunt trauma has been very low (e.g. 1-2\%) and deemed futile when no sign of life (SOL) on admission [7]. However, some centers reported higher survival rates after blunt trauma (12\%) [8], with a collective review suggesting outcomes may be less dismal [4]. More recently, the German Trauma Registry reported a survival rate of $4.8 \%$ after blunt trauma, and $7.6 \%$ survival rate was reported in a US nationwide study based on administrative data [9]. However, the price of the occasional 'miracle [10]' continues to be debated [11, 12]. Also, indications and compliance to guidelines influence the outcome rates reported [13]. Quite clearly, deciding not to perform a resuscitative emergency thoracotomy in a situation where this would be (even only potentially in theory) lifesaving, is associated with an obvious $100 \%$ mortality [13].

Notably, performing a resuscitative emergency thoracotomy as a life-saving procedure is an urgent decisionthe dying patient cannot be transferred nor deferred for later intervention. Accordingly, almost half of all emergency thoracotomies in the German trauma registry are reportedly done outside the supra-regional trauma centers [14], with about $11 \%$ being done in a local hospital. Data from a busy region in the United States covering 28 hospitals found that 10 centers did on average $<2$ such procedures per year- 3 of these centers were designated as level I [14]. Hence, this procedure is-more often than not-done at low-frequency and with little regularity in real-life practice for many surgeons. To mitigate this, educational strategies and deliberate training would be necessary to optimize performance and enhance the chance for a favorable outcome. Being prepared is of the essence to provide timely care in an emergency.

The aim of this study is to describe the systematic changes to education and training over time in a maturing trauma system and its association with indications and outcomes in one time-critical and potentially life-saving yet rare emergency procedure for critically ill trauma patients.

\section{Methods}

The study is based on the clinical evaluation of two previously reported consecutive cohorts $[15,16]$. These two cohorts describe the patient characteristics and outcomes for resuscitative emergency thoracotomy. In the current study, we describe the concurrent institutional and structural changes to the trauma system with particular focus on the education and certification of health care providers in our system over a long time period.

\section{Ethics and study design}

The study is a quality assurance project, hence not subject to formal review for acceptance by the Regional Ethics Committee (REK Helse Vest). The project was approved by the Institutional Data Protection Officer (Personvernombudet, SUS) at Stavanger University Hospital (SUH), as required by institutional protocol. As an observational study, the STROBE guidelines were consulted and applied, where applicable [17].

\section{Study hospital and population}

Stavanger University Hospital is one of the largest (in patient volume) trauma hospitals in Norway and has a primary catchment area of about 375.000 inhabitants as sole health care provider, but receives patients from several counties and hospitals beyond the primary catchment area (about 500-600 K) due to availability of prehospital care services (one air-ambulance helicopter and one search-andrescue helicopter is located in Stavanger), neurosurgical and neurointensive care capacity and surgical intensive care resources and a busy interventional radiology service in addition to 24/7/365 surgical services covering trauma care. The epidemiology of the trauma deaths and the injured population in our region has been described in detail previously [18-21], as has the trauma team activation (TTA) criteria and the use of a 2-tiered TTA approach [22]. SUH has had a local trauma registry in place since 2004 [22] and an additional fracture registry since 2006 [23]. Briefly, the registry includes several standard metrics of injured patients, such as injury severity score (ISS), New ISS (NISS), Revised trauma score (RTS) [24] and probability of survival (Ps) calculations per TRISS methodology $[25,26]$, as previously described [22]. 


\section{Time interval and incremental periods}

The study includes all emergency thoracotomies from January 1st, 2000 to December 31st, 2018, as described in detail in two previous studies $[15,16]$. For sake of the current investigation, the study period is split into 3 timephases as the 'early' (2001-2005), the 'developing' (2006-2011) and the 'mature' (2012-2018) period. This distinction is arbitrary yet represents time spans during which several changes occurred. The first time period ("early phase") coincide with the initial report [15] during which no formal trauma system existed nationally, regionally and was based on local enthusiasts. The subsequent time periods defined as 'developing' and 'mature' coincides with the second report [16] on emergency thoracotomy in trauma patients. The 'developing' phase was chosen for its initial formal attempt at shaping the trauma system, both nationally and regionally. The latter and 'mature' phase represents the period during which many of not most structures were implemented (See Table 1 for details).

\section{Systems change over time with increased focus on education, training and simulation}

Trauma surgery is not a designated specialty in Norway [27], nor is "acute care surgery". Hence, general surgeons and designated subspecialties (typically gastrointestinal surgeons; vascular surgeons) are the ones responsible for trauma care [28].

During the study period, an increased effort was placed on certification of all surgical trainees in ATLS-principles
[29], as well as the faculty/staff surgeons (Table 1). The specific contributions to certification, training and system evolution are presented, giving an overview of critical elements in developing both individual skills and teamtraining for a general overview, rather than an exhaustive list. Several animal training courses were held and attended over the period (live pig model) as part of the mandatory "War Surgery" course during surgical training, and later also as part of Definitive Surgical Trauma Course $\left(\right.$ DSTC $^{\mathrm{TM}}$ ) or similarly structured trauma training (porcine model for hemostatic emergency procedures in trauma $[30,31])$ with a complete local operating team attending to enhance team training and dynamics [30, 31]. Other local or regional courses (e.g. skills training in laparoscopic abdominal surgery) were exploited for double purposes, e.g. the animals where used to practice emergency procedures as an integrated part of the training after the laparoscopy training was completed.

Cadaver training at the Department of Pathology commenced in the early phase in an ad hoc manner and, subsequently, was structured and systematically implemented during the development phase. Initially, emergency thoracotomy, thoracic drains, abdominal and pelvic packing was practiced, and other procedures were added to the spectrum during the later phase.

Simulation in teams through local adaption of the BEST team-training concept (BEtter and Systematic Trauma training $[32,33])$ was initiated and eventually has become a regular, weekly event in the hospital [34]. This focuses primarily on team interaction, situational awareness, communication (such as; clear messages; closed loop

Table 1 Implementation of certification and training over 3 temporal phases

\begin{tabular}{|c|c|c|c|}
\hline Phase & Early & Developing & Mature \\
\hline Incremental time-period & 2001-2005 & $2006-2011$ & $2012-2018$ \\
\hline $\mathrm{ATLS}^{\mathrm{TM}}$ certification & some & most & all \\
\hline ATLS instructors and courses & none/few & some & $\begin{array}{l}\text { Several } \\
+ \text { local courses }\end{array}$ \\
\hline $\mathrm{DSTC}^{\mathrm{a}}$ participation & rare & some/most & all \\
\hline Trauma team activation & 1-tier & 1 -tier $\rightarrow$ 2-tier & 2 -tier \\
\hline Team simulation training & none & occasional & weekly \\
\hline Cadaver procedure training & none & occasional & regular/weekly \\
\hline Trauma audits & Ad hoc & regular & regular \\
\hline SUH Trauma Registry & $2004 \rightarrow$ & $\rightarrow$ & $\rightarrow$ \\
\hline \multicolumn{4}{|c|}{ Concomitant national changes to trauma system } \\
\hline National trauma plan & none/ad hoc & $v .1(2006)$ & $v .2(2016)$ \\
\hline Nat'l advisory unit on trauma & & & Est. $2013 \rightarrow$ \\
\hline National Trauma Registry & none & None & Est. $2014 \rightarrow$ \\
\hline
\end{tabular}

${ }^{a}$ Either as DSTC courses or similar (e.g. practice of hemostatci emergency surgery on a live pig model; course on warsurgery) 
communication etc.) and the non-technical skills of trauma management using live mannequins and cases from the local registry for simulation.

\section{Statistical analysis}

Statistical analyses were performed by IBM SPSS for Mac v. 26. (Statistical Package for Social Sciences; Armonk, NY, USA: IBM Corp). Descriptive data were analyzed using on-parametric tests, using Kruskal-Wallis for analyses of continuous data across the 3 time-periods, or Chisquare for trend ( 2 degrees of freedom) for categorial variables. All tests were two-tailed, and statistical significance attributed to $P<0.050$.

\section{Results}

During the study period, there were a total of 36 injured patients who had an emergency thoracotomy (Fig. 1). The year-on-year number of procedures and associated system changes are presented in Fig. 2. On average, 2 procedures per year were performed. For the complete study period, the median age was 40 years (iqr 24-57), 27 were men (75\%). Injury severity score (ISS) was median 40 (iqr 30-57), and NISS was median 57 (iqr 49-66). The median RTS (revised trauma score) on admission was 3.0 (iqr 0.0-7.0), with $23(64 \%)$ presenting with SOL on admission. The probability of survival $\left(\mathrm{P}_{\mathrm{s}}\right)$ was estimated at a median of $6.4 \%$ (iqr $1.1-29.5 \%$ ) for all patients.

The overall relationship between age of patients and their corresponding injury profile demonstrated a shattered distribution with no clear-cut pattern or correlation (Supplementary Fig. 1 ).

The patient characteristics and injury data for each time period are presented in Table 2. As shown, the number of survivors increased (Fig. 2) with each time period, as did the rate who had SOL on admission (from 40 to $77 \%$ ) while the number of 'elderly' $>55$ years subject to an emergency thoracotomy decreased (Table 2). Most other characteristics remained unchanged throughout the period (Table 2, Fig. 3). In Fig. 2, some of the time-critical events in trauma education and training for developing and maturing of the trauma system and hospital preparedness are presented.

\section{Discussion}

In this study, we present structural and temporal changes to trauma team training consisting of team simulation and procedure training developed through 3 phases of trauma system development and maturation. We demonstrate improved outcome for one time-critical emergency procedure done at low frequency during this time period, associated with concurrent changes in trauma team and individual skills training. While this association is not

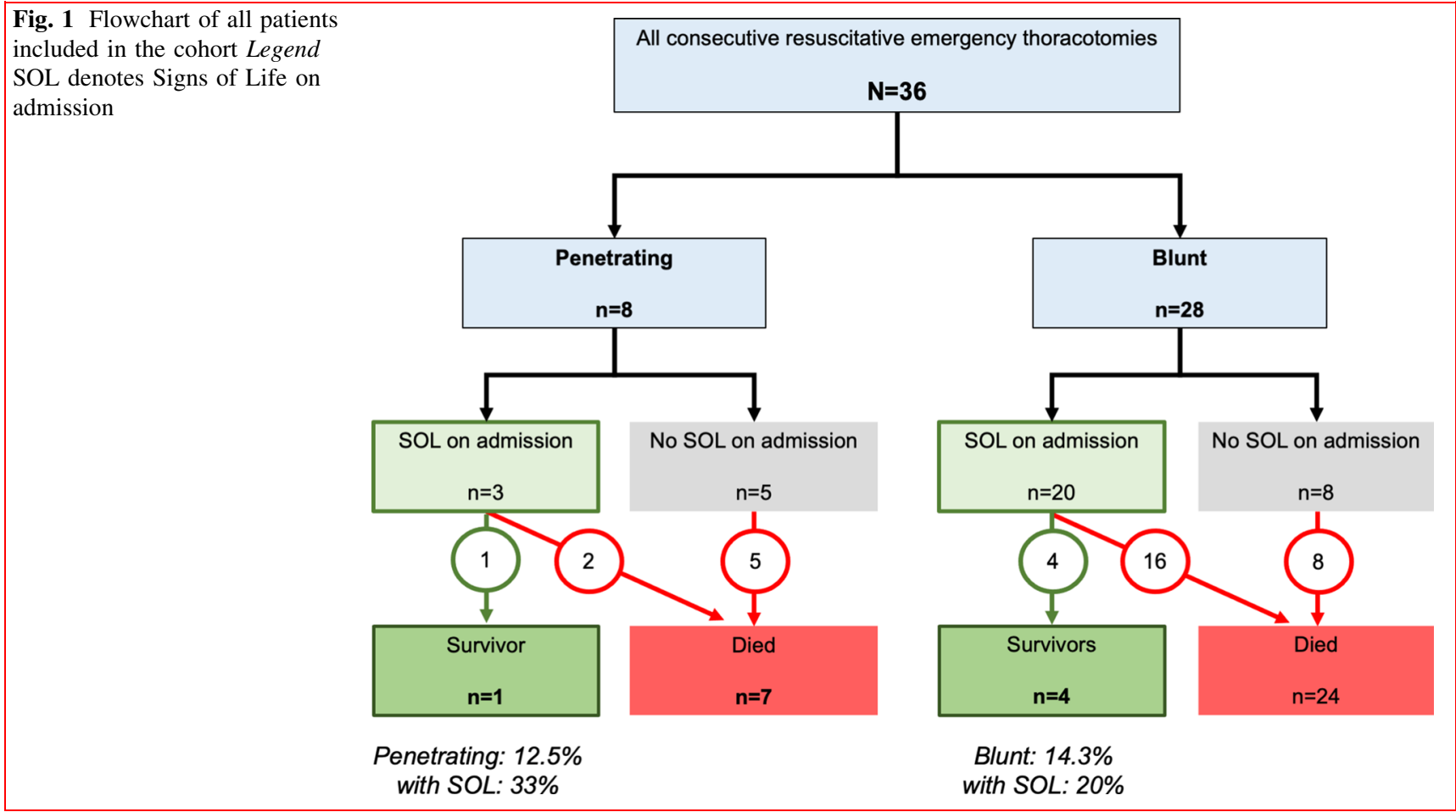


Fig. 2 Time-dependent phases of change and associated outcomes Legend DSTC denotes 'damage surgical trauma course' or similar courses on hemostatic trauma surgery procedures on a live porcine model; ATLS denotes advanced Trauma Life Support; BEST denotes Better and Systematic Trauma training. Please see maintext for details


intended to suggest a direct causality link, we believe it supports the role of structured training and simulation in trauma care by the associated outcomes.

Indications have slightly changed over time, indicated by fewer elderly patients and fewer patients with no SOL on admission subject to emergency thoracotomy. This should be viewed as a wanted effect of the focused training and education. Clearly, the elderly have less physiological reserve and for any emergency surgery and trauma intervention one should carefully consider the balanced riskbenefit to avoid futility [35]. One US study found no survivors in patients $>57$ years of age who underwent emergency thoracotomy [36]. Of note, the two oldest survivors in the current series were 55 and 68 years, respectively. We had no survivors in any of the very elderly patients $(77,85$ and 90 years) having emergency thoracotomies performed, although 2 of 3 had SOL on admission and thoracic injury as LOMI. These patients had high ISS and NISS score, and all had sustained blunt injury mechanisms. We conclude that emergency thoracotomy would best be withheld in similar cases in the future. We also concur with the proposed guidelines [37] that when (a) prehospital CPR exceeding $10 \mathrm{~min}$ after blunt trauma without a response, (b) prehospital CPR exceeding $15 \mathrm{~min}$ after penetrating trauma without a response, and (c) when asystole is the presenting rhythm, and there is no pericardial tamponade there is no indication of resuscitative emergency thoracotomy as the outcome is considered futile.

The low frequency at which this procedure is performed is one of the barriers to both practice evaluation and outcome assessment. However, the rarity of the procedure may reflect the real-life situation in many geographical regions, even in level I centers. In rural and less densely populated regions this event may be rare, but may still produce favorable outcomes, such as reported in a study from Iceland [38]. In Germany, almost $50 \%$ of all emergency thoracotomies were done outside the supra-regional trauma centers [14], with one in ten done in a local hospital. Moreover, in a recent study from the Pennsylvania trauma system covering 28 hospitals, some 10 centers did on average $<2$ procedures/year ( 3 of which were designated level I centers) and only 3 centers consistently did $>10$ procedures per year [14]. Consequently, the rarity of this procedure and the urgency of its nature do not permit a 'centralization' as a remedy to increase the chance of success for critically injured patients. We believe that training and simulation are key to enhance performance.

Stavanger University Hospital has had a long-standing focus on the trauma chain of survival[39] from prehospital to rehabilitation, with several faculties involved in core trauma topics ranging from prehospital care [40-42] and resuscitation $[43,44]$ to injury management. Compared to the US and other mature systems, trauma systems in Scandinavia may have only matured more recently [45], and the study period has seen several structural changes in Norway, including commencement of a national trauma plan (first version in 2006, revised in 2016) with designated centers for trauma care yet a somewhat slow adoption. While implementation has been documented to be slow among local hospitals [46], no similar quality assessment has been done for all of the trauma centers. 
Table 2 Patient and procedure characteristics during 3 phases of system development

\begin{tabular}{|c|c|c|c|c|}
\hline Characteristics & Early & Developing & Mature & $P_{T R E N D}^{\mathrm{a}}$ \\
\hline Period & 2001-2005 & 2006-2011 & 2012-2018 & n. $a$ \\
\hline Years $(n)$ & 5 & 6 & 7 & \\
\hline Procedures $^{\mathbf{b}}, n$ & 10 & 13 & 13 & 0.279 \\
\hline Survivors & 0 & 2 & 3 & \\
\hline Gender & $3: 7$ & $4: 9$ & $2: 11$ & 0.605 \\
\hline \multicolumn{5}{|l|}{ Female:Male } \\
\hline Age (median, iqr) & $51(24-59)$ & $34(23-65)$ & $45(24-51)$ & 0.077 \\
\hline$>55$ years, $\mathrm{n}(\%)$ & $5(50 \%)$ & $5(31 \%)$ & $1(7.7 \%)$ & \\
\hline \multicolumn{5}{|l|}{ Mechanism } \\
\hline Blunt & 7 & 11 & 10 & 0.702 \\
\hline Penetrating & 3 & 2 & 3 & \\
\hline Injury severity & $35(26-52)$ & $50(37-59)$ & $35(23-62)$ & 0.207 \\
\hline \multicolumn{5}{|l|}{ ISS (median, iqr) } \\
\hline NISS (median, iqr) & $57(46-68)$ & $66(50-66)$ & $50(34-62)$ & 0.255 \\
\hline RTS, admission & $0.0(0.0-4.8)$ & $3.0(0.5-8.0)$ & $6.0(0.0-8.0)$ & 0.801 \\
\hline \multicolumn{5}{|l|}{ Median, iqr } \\
\hline LOMI $(n)$ & 4 & 10 & 9 & 0.166 \\
\hline \multicolumn{5}{|l|}{ Thoracic } \\
\hline Any other & 6 & 3 & 4 & \\
\hline SOL on admission Present, $n(\%)$ & $4 / 10(40 \%)$ & $9 / 13(69 \%)$ & $10 / 13(77 \%)$ & 0.166 \\
\hline TRISS (mean) & 19.1 & 15.7 & 31.4 & 0.422 \\
\hline $\mathbf{P}_{\mathbf{S}}$ in $\%$ (median, iqr) & $4.4(0.5-27.9)$ & $6.8(0.2-20.4)$ & $8.4(0.8-65.4)$ & 0.877 \\
\hline
\end{tabular}

Data are presented as median (interquartile range, IQR) if not otherwise stated

${ }^{a} \mathrm{P}_{\text {trend }}$ indicating differences between groups investigated as a trend between time periods

${ }^{\mathrm{b}}$ Resuscitative emergency thoracotomy; either as anterolateral thoracotomy, sternotomy or clamshell

ISS denotes injury severity score; NISS denotes New injury severity score; Ps (denotes probability of survival from the Trauma revised injury severity score; TRISS); RTS denotes revised trauma score; LOMI denotes 'Location Of Major Injury'; SOL denotes "signs of life" on admission

Demonstrating a real effect of the efforts put into training and education is difficult and near impossible in terms of return on saved lives and limbs. Hence the discussion of ATLS-principles [29, 47-49], teaching practices and the impact beyond confidence boosting for the trainee. Still, we practice because we believe in return on investment. Continued training also makes sense in the light of increased focus on competence-based practice derived from deliberate training [50]. While hard to prove, we believe the current study may point to return on investment due to an increased and steadfast focus on systems improvement year-on-year in our hospital. We believe this practice to be transferrable to other hospitals and other settings, independent of geography and population density.

Some limitations of the study have to be addressed. One is the small number of patients over a long time. However, this would be the case for the majority of hospitals that receive injured patients. Measuring effect of structured training to such a rare procedure can hardly be done through trials of any sort. Of note, we prospectively collected data since 2004 in the trauma registry. Further, due to the low number of events, statistical power does not allow to draw any causality beyond associations. Nonetheless, we have found associations with the time periods and maturing of the trauma center, however, we do not claim any direct causality. Despite the low volume, we believe the data can be used by several other hospitals to encourage systematic and structured trauma training. Also, even some trauma centers in the US have comparable low volumes of these procedures, so incentives to practice and improve should be present across all levels and domains.

\section{Conclusion}

Increased focus on training and simulation and maturation of the trauma system was associated with improved outcome for a rare, but potentially life-saving intervention. 
Fig. 3 Age distribution and probability of Survival according to 3 time-dependent phases. Legend a The median age across the entire period was 40 years (blue, dotted line), with no significant difference between time-periods. In $\mathbf{b}$ is shown a non-significant increase in Ps over time, particularly for survivors. The median Ps value was very low (median Ps at 6.4\%) for the entire cohort (blue, dotted line) indicating a critically ill and severely injured population
A

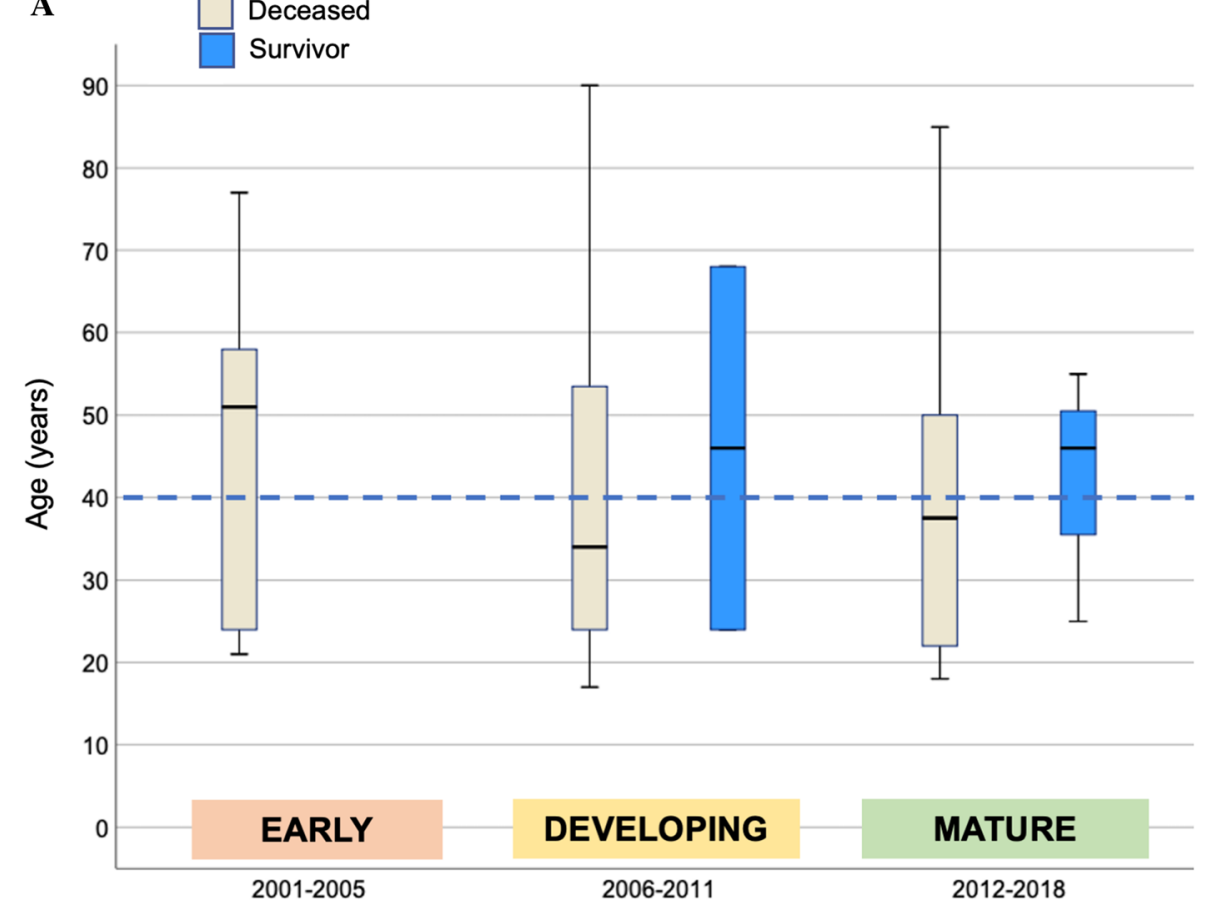

B

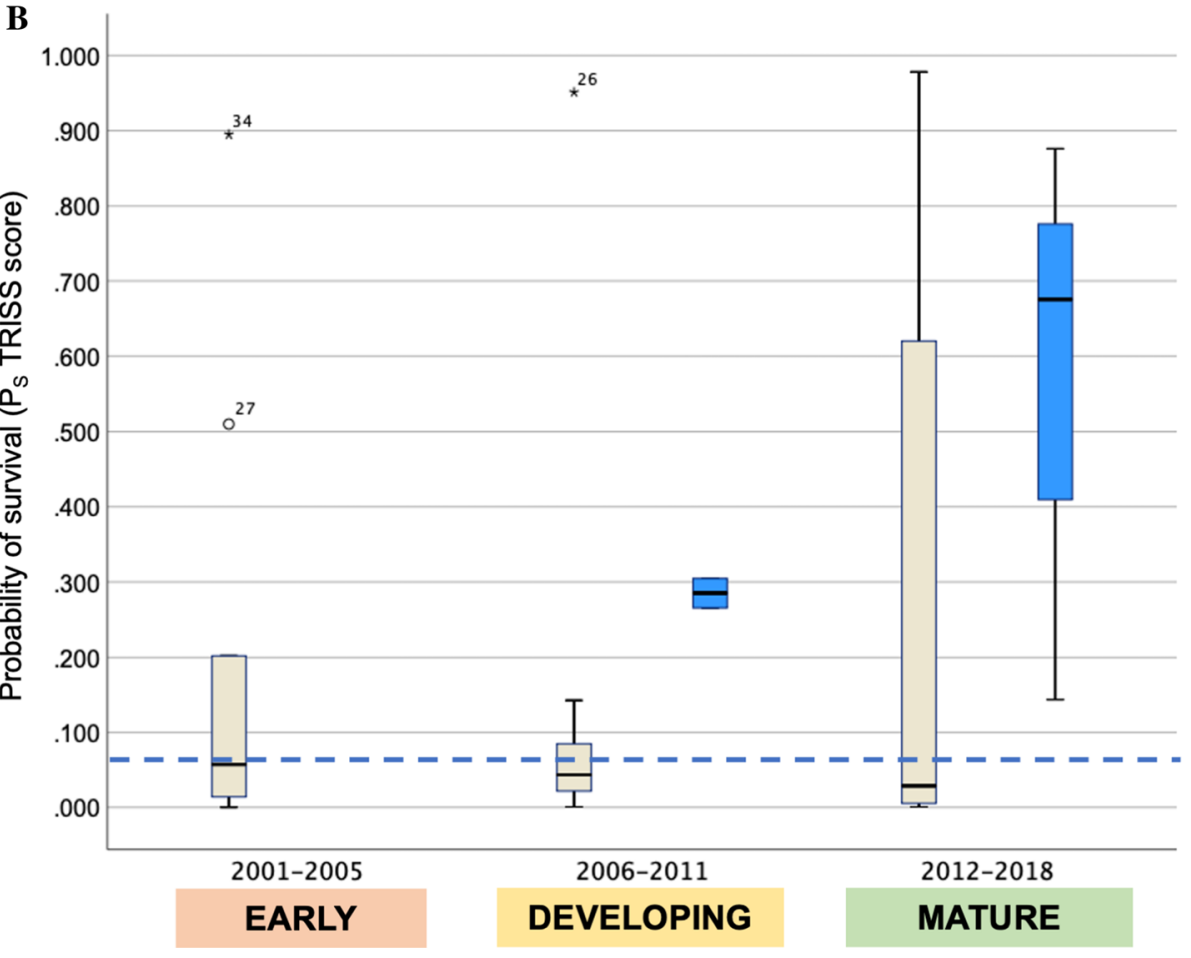


While causality cannot be claimed, the findings may be transferrable to similar settings and may encourage training and deliberate practice to enhance performance.

Acknowledgement This paper is based in part on an invited lecture (by K.S.) held at the Royal Australasian Congress of Surgery RACS 88th Annual scientific congress, May 2019 in Bangkok, Thailand.

Funding Open Access funding provided by University of Bergen.

\section{Compliance with ethical standards}

Conflicts of interest The authors declare that they have no conflict of interest.

Open Access This article is licensed under a Creative Commons Attribution 4.0 International License, which permits use, sharing, adaptation, distribution and reproduction in any medium or format, as long as you give appropriate credit to the original author(s) and the source, provide a link to the Creative Commons licence, and indicate if changes were made. The images or other third party material in this article are included in the article's Creative Commons licence, unless indicated otherwise in a credit line to the material. If material is not included in the article's Creative Commons licence and your intended use is not permitted by statutory regulation or exceeds the permitted use, you will need to obtain permission directly from the copyright holder. To view a copy of this licence, visit http://creativecommons. org/licenses/by/4.0/.

\section{References}

1. Søreide K (2009) Epidemiology of major trauma. Br J Surg 96:697-698

2. Gondek S, Schroeder ME, Sarani B (2017) Assessment and Resuscitation in Trauma Management. Surg Clin North Am 97:985-998

3. Søreide K, Petrone P, Asensio JA (2007) Emergency thoracotomy in trauma: rationale, risks, and realities. Scand J Surg 96:4-10

4. Narvestad JK, Meskinfamfard M, Søreide K (2016) Emergency resuscitative thoracotomy performed in European civilian trauma patients with blunt or penetrating injuries: a systematic review. Eur J Trauma Emerg Surg 42:677-685

5. DuBose J, Fabian T, Bee T et al (2018) Contemporary Utilization of Resuscitative Thoracotomy: Results From the AAST Aortic Occlusion for Resuscitation in Trauma and Acute Care Surgery (AORTA) Multicenter Registry. Shock 50:414-420

6. Dumas RP, Seamon MJ, Smith BP et al (2018) The epidemiology of emergency department thoracotomy in a statewide trauma system: Does center volume matter? J Trauma Acute Care Surg 85:311-317

7. Hall BL, Buchman TG (2005) A visual, timeline-based display of evidence for emergency thoracotomy. J Trauma 59:773-777

8. Pahle AS, Pedersen BL, Skaga NO et al (2010) Emergency thoracotomy saves lives in a Scandinavian hospital setting. J Trauma 68:599-603

9. Panossian VS, Nederpelt CJ, El Hechi MW et al (2020) Emergency resuscitative thoracotomy: a nationwide analysis of outcomes and predictors of Futility. J Surg Res 255:486-494

10. Buchman TG (2012) The price of a miracle. J Am Coll Surg 214:25-26
11. Passos EM, Engels PT, Doyle JD et al (2012) Societal costs of inappropriate emergency department thoracotomy. J Am Coll Surg 214:18-25

12. Nunn A, Prakash P, Inaba K et al (2018) Occupational exposure during emergency department thoracotomy: a prospective, multiinstitution study. J Trauma Acute Care Surg 85:78-84

13. Søreide K (2016) A forensic inquiry into compliance to guidelines for emergency resuscitative thoracotomy in trauma: If the dead can't talk and the living won't tell, it is a story half told. Injury 47:1016-1018

14. Schulz-Drost S, Merschin D, Gümbel D et al (2020) Emergency department thoracotomy of severely injured patients: an analysis of the TraumaRegister DGU(®). Eur J Trauma Emerg Surg $46: 473-485$

15. Søreide K, Søiland H, Lossius HM et al (2007) Resuscitative emergency thoracotomy in a Scandinavian trauma hospital-is it justified? Injury 38:34-42

16. Thorsen K, Vetrhus M, Narvestad JK et al (2020) Performance and outcome evaluation of emergency resuscitative thoracotomy in a Norwegian trauma centre: a population-based consecutive series with survival benefits. Injury 51:1956-1960

17. von Elm E, Altman DG, Egger M et al (2008) The Strengthening the Reporting of Observational Studies in Epidemiology (STROBE) statement: guidelines for reporting observational studies. J Clin Epidemiol 61:344-349

18. Meling T, Harboe K, Søreide K (2009) Incidence of traumatic long-bone fractures requiring in-hospital management: a prospective age- and gender-specific analysis of 4890 fractures. Injury 40:1212-1219

19. Wiik-Larsen J, Thorsen K, Sandve KO et al (2020) Incidence and characteristics of pancreatic injuries among trauma patients admitted to a Norwegian trauma centre: a population-based cohort study. Scand J Gastroenterol 55:1347-1353

20. Heskestad B, Baardsen R, Helseth E et al (2009) Incidence of hospital referred head injuries in Norway: a population based survey from the Stavanger region. Scand J Trauma Resusc Emerg Med 17:6

21. Søreide K, Krüger AJ, Vårdal AL et al (2007) Epidemiology and contemporary patterns of trauma deaths: changing place, similar pace, older face. World J Surg 31:2092-2103. https://doi.org/10. 1007/s00268-007-9226-9

22. Rehn M, Lossius HM, Tjosevik KE et al (2012) Efficacy of a twotiered trauma team activation protocol in a Norwegian trauma centre. Br J Surg 99:199-208

23. Meling T, Harboe K, Arthursson AJ et al (2010) Steppingstones to the implementation of an inhospital fracture and dislocation registry using the AO/OTA classification: compliance, completeness and commitment. Scand J Trauma Resusc Emerg Med 18:54

24. Champion HR, Sacco WJ, Copes WS et al (1989) A revision of the Trauma Score. J Trauma 29:623-629

25. Schluter PJ (2011) The Trauma and Injury Severity Score (TRISS) revised. Injury 42:90-96

26. Champion HR, Sacco WJ, Hunt TK (1983) Trauma severity scoring to predict mortality. World J Surg 7:4-11. https://doi.org/ 10.1007/BF01655906

27. Søreide K, Glomsaker T, Søreide JA (2008) Surgery in Norway: beyond the scalpel in the 21st century. Arch Surg 143:1011-1016

28. Søreide K (2009) Trauma and the acute care surgery modelshould it embrace or replace general surgery? Scand J Trauma Resusc Emerg Med 17:4

29. Søreide K (2008) Three decades (1978-2008) of Advanced Trauma Life Support (ATLS) practice revised and evidence revisited. Scand J Trauma Resusc Emerg Med 16:19

30. Hansen KS, Uggen PE, Brattebø G et al (2007) Training operating room teams in damage control surgery for trauma: a 
followup study of the Norwegian model. J Am Coll Surg 205:712-716

31. Hansen KS, Uggen PE, Brattebø G et al (2008) Team-oriented training for damage control surgery in rural trauma: a new paradigm. J Trauma 64:949-953 (discussion 953-944)

32. Wisborg T, Bratteb $\varnothing$ G, Bratteb $\varnothing \mathrm{J}$ et al (2006) Training multiprofessional trauma teams in Norwegian hospitals using simple and low cost local simulations. Educ Health (Abingdon) 19:85-95

33. Bratteb $\varnothing \mathrm{G}$, Wisborg T, Brattebo J et al (2001) Better trauma therapy-BEST or ATLS? Tidsskr Nor Laegeforen 121:505-506

34. Wisborg T, Bratteb $\varnothing$ G, Brinchmann-Hansen A et al (2008) Effects of nationwide training of multiprofessional trauma teams in norwegian hospitals. J Trauma 64:1613-1618

35. Søreide K, Desserud KF (2015) Emergency surgery in the elderly: the balance between function, frailty, fatality and futility. Scand J Trauma Resusc Emerg Med 23:10

36. Gil LA, Anstadt MJ, Kothari AN et al (2018) The National Trauma Data Bank story for emergency department thoracotomy: How old is too old? Surgery 163:515-521

37. Moore EE, Knudson MM, Burlew CC et al (2011) Defining the limits of resuscitative emergency department thoracotomy: a contemporary Western Trauma Association perspective. J Trauma 70:334-339

38. Johannesdottir BK, Mogensen B, Gudbjartsson T (2013) Emergency thoracotomy as a rescue treatment for trauma patients in Iceland. Injury 44:1186-1190

39. Søreide K (2012) Strengthening the trauma chain of survival. Br J Surg 99(Suppl 1):1-3

40. Busch M (2006) Portable ultrasound in pre-hospital emergencies: a feasibility study. Acta Anaesthesiol Scand 50:754-758

41. Søreide E, Deakin CD (2005) Pre-hospital fluid therapy in the critically injured patient-a clinical update. Injury 36:1001-1010

42. Lossius HM, Søreide E, Hotvedt R et al (2002) Prehospital advanced life support provided by specially trained physicians: is there a benefit in terms of life years gained? Acta Anaesthesiol Scand 46:771-778

43. Thorsen K, Ringdal KG, Strand K et al (2011) Clinical and cellular effects of hypothermia, acidosis and coagulopathy in major injury. Br J Surg 98:894-907

44. Søreide K (2014) Clinical and translational aspects of hypothermia in major trauma patients: from pathophysiology to prevention, prognosis and potential preservation. Injury 45:647-654

45. Kristiansen T, Søreide K, Ringdal KG et al (2010) Trauma systems and early management of severe injuries in Scandinavia: review of the current state. Injury 41:444-452

46. Dehli T, Gaarder T, Christensen BJ et al (2015) Implementation of a trauma system in Norway: a national survey. Acta Anaesthesiol Scand 59:384-391

47. van Maarseveen OEC, Ham WHW, van de Ven NLM et al (2020) Effects of the application of a checklist during trauma resuscitations on ATLS adherence, team performance, and patient-related outcomes: a systematic review. Eur J Trauma Emerg Surg 46:65-72

48. Mohammad A, Branicki F, Abu-Zidan FM (2014) Educational and clinical impact of Advanced Trauma Life Support (ATLS) courses: a systematic review. World J Surg 38:322-329. https:// doi.org/10.1007/s00268-013-2294-0

49. Jayaraman S, Sethi D, Chinnock P, Wong R (2014) Advanced trauma life support training for hospital staff. Cochrane Database Syst Rev. 2014(8):CD004173.

50. Skjold-Ødegaard B, Søreide K (2020) Competency-based surgical training and entrusted professional activities-perfect match or a procrustean bed? Ann Surg. https://doi.org/10.1097/SLA. 0000000000004521 . [Online ahead of print].

Publisher's Note Springer Nature remains neutral with regard to jurisdictional claims in published maps and institutional affiliations. 